\title{
Study on the Semantic Expression of Woven Fiber Art Decoration
}

\author{
Zhenzhu Wang ${ }^{1, *}$, Yuwan $\mathrm{Ma}^{1}$
}

\author{
${ }^{1}$ Shanghai university, Shanghai, China \\ *Corresponding author. Email: 1603175449@qq.com
}

\begin{abstract}
In the long history of the pentium, weaving technology carries all the civilization of human production and life.The history of when weaving technology was invented and used by people is still uncertain, and because it cannot be preserved for a long time like stone tools, ceramics and metal products, the records about weaving technology cannot be systematically investigated and verified, but it still cannot hide its shining stars in the history of human civilization. Woven tapestry as traditional fiber art form, the heavy burden of carrying on the past heritage, therefore, this article will begin from tapestry historical evolution, tapestry through the analysis of the research process and form of expression, gradually delve into woven decoration features and technique of expression, mining woven fiber art inspiration, to explore the possibility of more decorative performance semantics.
\end{abstract}

Keywords: Fiber art, Weaving, Decorative performance

\section{INTRODUCTION}

Fiber art is a new artistic theory which develops continuously on the basis of the ancient tradition of weaving. The term "fiber art" first appeared in the United States in the 1970s. Steps forward, with the passage of time, the history to weave as the means of this art form to start the new development and extension, artists began to explore the fiber material and process of the language and aesthetic feeling, which broke through the warp/weft weaving single production means, create a subversion of traditional art, art in the 20th century, under the influence of It has opened up a new world of fiber art.

\section{HISTORICAL TRACE OF WOVEN FIBER ART}

In the earliest rope-tying records, the primitive humans covered themselves with leaves, grass, hemp and animal skins for shelter, so we can speculate that the fiber weaving technology has already appeared in the period prior to the ancient Babylonian and Egyptian pyramidal civilization. In a matrilineal society, the Yangshao Culture of the Yellow River basin, net-like pottery (as shown in figure 1) shows that primitive humans drew inspiration from biological activities such as spiders' webs and birds' nest-building to form the earliest weaving skills. Then in the thousands of years after the long years, the surviving objects and skills of inheritance to us laid a search for tapestry art a broad road.

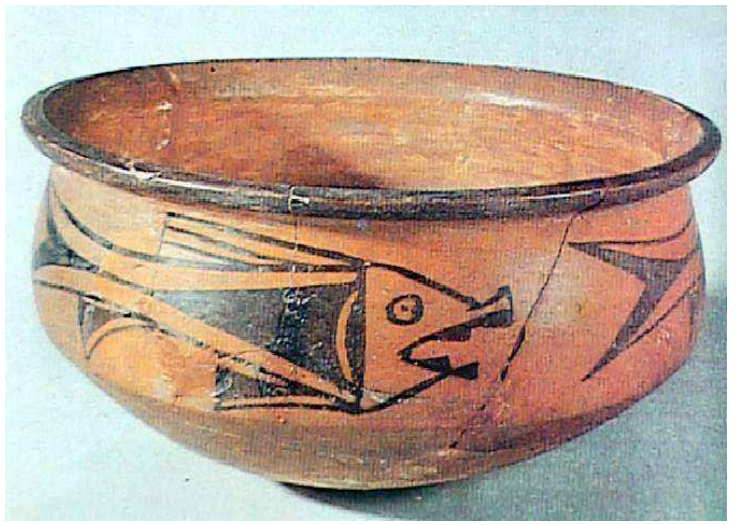

Figure 1 Pottery

From the 12th century to the beginning of the 16th century, the prevalence of Christianity in Europe gave birth to the artistic concept representing the ideology and material culture of the city in this period -- Gothic art. During this period, large woven carpets with religious themes brought temperature to the cold church walls. In addition to the practical function of moisture protection and warmth, they also had the political function of spreading doctrines and reflecting people's ideas and emotions. The technical characteristics of the tapestry of the Middle Ages in Europe are mainly reflected in the decorative patterns, such as the geometric patterns of the cross, sheep and fish, which show the religious nature of the early Christian period. In Byzantium period, lions, horses, hunting, peacocks and other realistic figures 
appeared, as well as bead patterns and twine decorative patterns. In the Roman period, complex character depiction and large religious plots appeared, which greatly improved the requirements for weaving techniques. At that time, the famous convex thick satin was woven with silk and linen. At that time, the famous convex thick satin was woven with silk and linen. The design combined the advantages of Gothic naturalism and Chinese silk patterns, with elegant patterns, fresh and natural color matching, and very Oriental charm. Around $1200 \mathrm{AD}$, outside excluding religion, tapestry performance content still has the life scene such as noble feasting, hunting, more secularized, life.

Renaissance art period, people began to use tapestry art performance painting subject matter, with painter painting as the imitation, performance of war, aristocratic life and poor labor scene, weaving skills as fine degree and color refinement gradually improve. During the Baroque and Rococo periods of the seventeenth and eighteenth centuries, tapestries were widely used in the interior decoration of palaces. The use of gold and silver threads made the tapestries more resplend, and in order to more harmoniously blend into the architectural space, the exquisite frame of stereoscopic effect was specially added for the tapestries, which had both aesthetic and practical functions.

In the mid-19th century, William Morris advocated that tapestry weaving should return to the flat surface and break from the rigid depiction of paintings. In addition, Morris strongly advocated textile printing and dyeing and fiber weaving, and called attention to the physical beauty of woven fabrics through the touch of materials and the interweaving of warp and weft through the initiation of the handicraft movement. In the early 20th century, Bauhaus artists brought a unique understanding and pursuit to tapestry weaving design.Gunter Stelzer, a student at the time, was an outstanding example of the Bauhaus art style. In her works, the patterns, large and small, show rich and harmonious abstract geometrical shapes through dense and well-arranged lines. Moreover, the thickness, softness and smoothness of the material fully release the texture beauty of the material itself, add the aesthetic experience of tactile factors, and unify the material, shape and spirit of the work.

In 2006, through the tireless efforts of Jean Lurcat and many others, in lausanne, successfully hosted the first international tradition and modern, tapestry art biennale exhibition exhibits from all over the world, and the author involved in various fields, though mural form used a combination of painting and weaving process, but compared with the traditional tapestry weave form, nature prefer to personality, The colour characteristic of lively contrast highlights gradually. In the second and third sections of the Lausanne Biennale in 1965 and 1967, the transformative weaving techniques and pluralism of materials made graphic fibre art no longer unique. Synthetic fiber materials brought by industrial development inject fresh blood into tapestry weaving, and tapestry art that stays in the plane is also transformed by a more open art environment. In the following several Lausanne Biennale, three-dimensional art forms and even fibrous art that breaks the space limit emerge in an endless stream.

In 2000, the first "From Lausanne to Beijing" Fiber Art Exhibition was held in Beijing. Artists and educators of fiber art from all over the world gathered here. The works exhibited in different forms were brilliant. This undoubtedly plays a significant role in promoting the development of modern fiber art.

\section{EXPLORING THE CREATIVE EXPRESSION OF WEAVING AND DECORATION}

\subsection{Draw inspiration from nature}

The earliest weaving forms of fiber art originated from nature. In primitive civilization, people obtained living conditions from nature, worshipped nature, and extracted totem as the earliest weaving patterns. Splashing mountains and water, spring, summer, autumn and winter, and the changing of the sun and moon provide rich materials and inspiration for artistic creation. The tens of millions of creatures in nature also provide direct and indirect inspiration for fiber art creation. At the same time, the fiber raw material can be harvested in nature.

Fiber artists use natural fibers and natural materials to double shape the natural state and natural color to express their attachment to and reverence for nature, and emphasize the harmonious coexistence between human and nature.

\subsection{National culture and inheritance}

No matter in which period, the development of fiber art has a great relationship with other art forms at that time, and even derives motive power from it. For example, the original fabric art of weaving came from basket-weaving techniques. European Renaissance period, the design of tapestry undertakes trace to painting work to wait a moment more through. Moreover, individual fiber artists are inspired by different inspirations in the process of creation, and need to consider the requirements of service objects. In addition, other art forms also affect the development of fiber art, such as stage art, installation art, conceptual art, performance art and other cultural and artistic differences provide a lot of inspiration material library for the creation of fiber art.

\subsection{Social progress and scientific and technological development}

The progress of science and technology is a good means to optimize the way of human existence, and it also promotes economic development. Network engineering, genetic engineering, biological engineering 
and other new technology applications provide more man-made fiber materials, and the performance is more diversified and stable. Digital weaving technology and digital printing technology are becoming more and more mature, which greatly improves the problems of long time and low output of pure handmade weaving, and gradually forms an industrial chain for the commercial development of fiber art. The scientific spirit emphasizes rational values and also provides a new direction for fiber art creation. Therefore, we should pay more attention to the great influence brought by science and technology culture and realize the sustainable innovative spirit of fiber art development.

\section{RECONSTRUCTION OF FIBER DECORATIVE LANGUAGE -- A VISUAL INNOVATION METHOD}

\subsection{Ideological shaping}

Conceptual art, also known as ideological art, originated from the artistic trend of thought in the middle of the 20th century. As the expression form of modern art, woven fiber art is used by the creator to convey the original intention and self-concept to the audience. In the way of expression, regardless of the media and style, it usually adopts the way of ready-made products, intervention products, literature and words.

Semantic expression is usually the following three ways.

First, embezzlement replacement. Generally speaking, conceptual art usually uses existing media for transformation, and then the artist applies it to the resource situation of the work. The appropriated part is often symbolic or metaphorical, which serves as a metaphor for the connection between social culture, economic background and space-time concepts. Through this method, the works are concise and powerful, interesting and intuitive. However, this method lacks some innovation and is largely limited by the original nature, and its concept and form are also superficial and straightforward.

The second is tampering and replacement. The form of the work is replaced by collage, daub and combination, so that the final product has obvious contrast. This approach is more subversive and playful than appropriation. In traditional resources into the specious contemporary art language, a simple embodiment of the "anti-orthodox" revolution. This is undoubtedly the transformation of the form, still not easy to break through the shackles of the situation of original resources, attached to the concept of original resources. If you want to go beyond the original resources, you need to start from creativity and ontology, to replace and alter the original resources to achieve the transformation of form, so as to achieve a new aesthetic thinking and philosophical meaning.
Third, transformation and reconstruction. After mastering the traditional resources, integrate the new creation with the new form language, break away from the original resource materials, and form the personal style. Transformation and reconstruction is to transform the accumulation of cultural experience in traditional resources into internal consciousness, combine with the complete system constructed in the artist's brain, and at the same time be influenced by the experience and preferences of the artist, forming the unique style language of the artist. The art language of "differentiation" is recreated to bring different visual feelings to the viewers, and at the same time, let the viewers know the profound charm of the works in the exploration to cause empathy. The creative formal language has shaped the stylistic characteristics besides the conceptual content and perfected the historical significance of conceptual art.

\subsection{The shaping of humanity}

"Humanistic" man can be either an individual or a whole. Similarly, human culture can also be divided into individual culture or whole culture. Thus, humanism includes human culture and human nature in culture. Humanism is the noumenon and extension of humanism in the final analysis. Humanistic spirit enables people to pay attention to life, promote the exploration of the ultimate meaning of life, and pursue a deep spiritual vision. In fiber art, works with different styles set up unique humanistic meaning, reflecting the inseparable relationship between artistic and humanistic nature and win-win cooperation. In the application of art, humanistic semantics can directly imitate the real world, and can also trace back to the history and imagine various plans of the future world. By means of visual and touchable expression, the author highlights the evaluation of the objective world and the true feelings of the author in a dynamic or static way, and conveys views and understandings to the audience.

\subsection{Material representation and semantic shaping}

As the most important factor of fiber art, the material gives the works a distinct personality because of its unique expressive meaning. However, from the perspective of the effect presented by fiber art, the diversity of material properties also brings differences in the expression of semantics. First of all, different materials produce different texture effects in different manufacturing processes. These textures may show a warm/cold contrast, wet/dry contrast, hard/soft contrast or light transmittance. Secondly, the sense of volume of materials should also be taken into consideration. The vision will get different perception according to the volume size, thickness and so on. Its density, order and rhythm will release the artistic conception consistent with the environment in the audience's vision, touch and psychology. 


\subsection{Symbolic representation and semantic shaping}

Symbolic semantics have been widely used in traditional fiber art to reflect the concept and aesthetics of a certain period. Traditional fiber art presents a natural soft, warm and safe attribute in the whole, and it is this characteristic that defuses the coldness of architecture. For the selection of fiber art materials, artists tend to choose natural raw materials and express their reverence for the ecological nature by manual means. It is a popular practice at home and abroad to turn words into symbols to express meaning. It focuses on and examines the profound connotation of culture by means of the linguistic meaning of written signs, differentiates the signifier and the signified of written signs, and constructs the level of signifier by means of artistic language.

\section{CONCLUSION}

In addition to presenting people's visual feast and delicate sense of touch, its weaving expression language has a deep image connotation and psychological meaning as well as the designer's emotional injection. This special connotation embodies the profound handmade emotion of human beings and carries the beautiful psychological feelings of people for thousands of years to the fiber material, which naturally becomes the carrier used by designers to express their design ideas today. It is easier to understand the emotional meaning of woven decoration semantics through full excavation. The design concept of expressing feelings and objects is of great benefit to design, which can not only deepen our understanding of the connotation of existing product design, but also deepen the cultural communication and identity.

\section{REFERENCES:}

[1] Lin Lecheng, Wang Kai, Fiber Art, [J] Shanghai: Shanghai Pictorial Publishing House, 2006

[2] Gong Jianpei. The Creativity and Expression of Fiber Art, [J] Chongqing: Southwest Normal University Press, 2006

[3] Wang Kai, Creativity and Evolution -- New Landscape of Fiber Art, [J] Beijing: China Architecture and Building Press, 2011

[4] Shi Hui. The 5th Space • Fiber and Space Art, [J] Hangzhou: China Academy of Art Press, 2009.

[5] Zhang Xuting. Study on the expression of multiple appearance texture based on different fiber braiding [D]. Dalian University of Technology,2012 